\title{
In Search for RIS3 for the Republic of Serbia: Challenges Between Theory and Reality
}

\author{
Đuro Kutlača ${ }^{1 *}$ \\ 1 Institute "Mihailo Pupin" Belgrade, Serbia
}

\begin{abstract}
Objectives of this paper are exploration of the challenges of use of methodology for creation of smart specialization strategy (S3) in Serbia. S3 is focused on use of knowledge for economic development. Major challenges of implementation of S3 in Serbia are weak links between R\&D sector and economy, and undeveloped culture of dialogue for adoption and realization of S3 priorities. In this paper are presented key challenges authors of S3 in Serbia are faced with in very first trial of introduction of S3 methodology in country. Paper is organized in four main parts. First part is (critical) description of the main concepts of methodology for creation of S3. The concept of S3 is a tool for realization of the strategy of the European development through "integrated industrial policy for the globalization era" and "Innovation Union". Second part will present implication of implementation of S3 in Serbia, i.e. conditions for use of one theoretical concept in reality of economy and society in Serbia. Third part is discussion of results of implementation of S3 in Serbia achieved so far (process is not finished at the moment of writing of this article, mid 2018), analysing challenges between proposed methodology and real situation in country. Fourth part is addressed to further steps in implementation of S3 in Serbia, with particular attention to the aspects of dialogue which should be organized between involved stakeholders in order to achieve consensus for adoption and realization of S3 priorities in Serbia.
\end{abstract}

Key words: Smart Specialization; S3 Strategy; MCDM methods; Priority Sectors; EDP; Dialogue

JEL Classification: A0, 033

\section{INTRODUCTION}

In the beginning of the year 2017 the Government of the Republic of Serbia has decided to launch activities addressed to creation of a Research and Innovation Strategy for Smart Specialization (RIS3). First steps in this direction were creation of three working groups: first, an Interministerial Working Body (IWB) for coordination of the activities between different ministries and governmental institutions; second and third working groups are established by IWB: the IWB has decided to establish an Analytical Team (AT) and an Operational Team (OT). The European Commission's (EC) Joint Research Centre (JRC) has supported these processes in partnership with the governments of Ukraine, Moldova and Serbia in developing RIS3 (government of Montenegro has joined activities six month later). The operational team consists of representatives of the Republican Secretariat for Public Policy, the Ministry of Education, Science and Technology Development, the Ministry of Economy, the Statistical office, the Serbian Chamber of Commerce and the National Employment Service. Their major tasks are operationalisation of activities for creation of RIS3 and communication between major stakeholders: government, research and innovation (R\&I) stakeholders, private sector, civil society, and JRC. The analytical team consists of representatives of the Institute Mihajlo Pupin

\footnotetext{
*E-mail: djuro.kutlaca@pupin.rs
} 
(IMP), Republic Statistical Office (RSO), and Republic Secretariat for Public Policy (RSPP) as well as some independent experts when needed. Their key activities are quantitative and qualitative analyses necessary for building a strong evidence-base for of RIS3.

This article is organized in four main parts. First part is (critical) description of the main concepts of methodology for creation of smart specialization strategy (S3). Second part will present implication of implementation of S3 in Serbia, i.e. conditions for use of one theoretical concept in reality of economy and society in Serbia. Third part will discuss results of implementation of S3 in Serbia achieved so far (process is not finished yet), analysing challenges between proposed methodology and real situation in country. Fourth part will be addressed further steps in implementation of S3 in Serbia, with particular attention to the aspects of dialogue which should be organized between involved stakeholders in order to achieve consensus for adoption and realization of S3 priorities in Serbia. Important note for readers is fact that in the moment of writing of this article (mid 2018), process of creation of RIS3 is in the beginning of mentioned dialogue, which is named by the authors of S3 methodology as Entrepreneurial Discovery Process (EDP).

\section{S3 METHODOLOGY}

The concept of "smart specialisation" is a tool for realization of the strategy of the European development through "integrated industrial policy for the globalization era" and "Innovation Union". S3 methodology is focused on use of knowledge for economic development, primarily is based on work of the expert group Knowledge for Growth (Foray, David \& Hall, 2009), and has rapidly been implemented in EU policy as precondition for use of structural funds. Elaborated by a group of academics in 2008, it very quickly made a significant impact on the policy audience, particularly in EU, as part of the preparation of the new Cohesion Policy for 2014-2020. Major presumption is that smart specialisation strategies can ensure a more effective use of public funds and can stimulate private investment. It is mainly addressed to regions (rather than country level) to concentrate resources to a few key priorities rather than spreading investments across all business sectors. They can also be a key element in developing multi-level governance for integrated innovation policies because of use of knowledge and creativity rather than manual work. Moreover, they have to be closely linked with other policy domains and require an understanding of regional strengths relative to other regions and the possible gains for interregional and transnational cooperation (European Commission, 2010).

The European Commission has established the S3 Platform in Seville, in order to support national and regional actors in the process of developing Research and Innovation Strategies for Smart Specialisation (RIS3), providing various forms of support, e.g. in terms of information, seminars, peer reviews and guidelines. Methodologically, process of development of S3 is organised in six practical steps for designing national or regional RIS3 (S3 Platform, 2012):

Step 1 - Analysis of the national or regional context and potential, in relation to other nations and regions;

Step 2 - Governance: ensuring participation and ownership - set up an inclusive structure and incentives for securing broad stakeholder involvement;

Step 3 - Vision - produce a shared vision among stakeholders - elaboration of an overall vision for the region;

Step 4 - Prioritisation - Identification of priorities - selection of a limited number of priorities for regional development;

Step 5 - Policy mix - Definition of a coherent policy mix, road maps and action plans combination of a mixture of policy measures and support them with road maps or action plans to secure implementation; 
Step 6 - Evaluation and monitoring - Integration of monitoring and evaluation mechanisms developing of systems for continuous and evidence-based monitoring of the process and follow up on results and effects, in order to learn and revise the policy mix.

\section{IMPLEMENTATION OF S3 METHODOLOGY IN SERBIA}

Serbia as candidate country for membership in EU is in permanent transition of economy and society since 1991, facing serious problems of unemployment, brain drain, ageing, and political instability (Semencenko \& Kutlaca, 2018). Major challenges of implementation of S3 methodology in Serbia are: weak links between $R \& D$ sector and economy; moderate level of innovation activities; undeveloped culture of dialogue between stakeholders involved in realization of S3 (Kutlača, Semenčenko and Nedović, 2016). Therefore, crucial support of JRC and foreign experts from FhG institute ISI (Karlsruhe, Germany), engaged (financed) by JRC is to overcome organisational weaknesses linking stakeholders and support process of selection of priority sectors of economy which development should be realised with use of knowledge, rather than manual work, or FDI. External support has resulted firstly with roadmap for development of RIS3 in Serbia in 2017-18. This roadmap is adaptation of originally proposed six steps into five phases (JRC and IWB, 2017):

Preparatory stage: Organisation of process of development of RIS3 in Serbia - resources necessary for effective cooperation between JRC and domestic institutions;

Mapping of economic, innovative and scientific potential: Multi-dimensional quantitative analysis showing strongest sectors and areas of science at regional level;

Entrepreneurial discovery process: Qualitative analysis and organized dialogue with all engaged stakeholders - EDP should be organized for all selected areas of smart specialisation;

Establish a monitoring and evaluation system: Development of indicators for monitoring of implementation and ex-post impact evaluation of RIS3 in Serbia;

Develop an implementation system: Organisation and financing of implementation of RIS3 in Serbia.

During the year 2017, and according to road map, major activities belong to phase 2 (or Step 1), i.e. both external experts and domestic Analytical teams were engaged in quantitative analysis of available statistical data with aim to identified priority sectors in economy of Serbia which development should be relied on R\&I activities. External experts (JRC and FhG) have developed procedure with two presumptions, based on already proved reach statistical bases with data available on regional level for NACE 3-digit categories of economic activities in Serbia ${ }^{1}$ :

(1) Quantitative analysis could and should be organised for four statistical regions in Serbia: Region RS11: Belgrade, Region RS12: Vojvodina, Region RS21: Šumadija and Western Serbia, Region RS22: Southern and Eastern Serbia (Region RS23: Kosovo - data are not available);

(2) Prioritisation of the sectors of economy within the regions should be based on their specialisation proper, i.e. an in relative terms higher importance of the sector in the regional economy than is calculated for the economy in Serbia. Measure for specialisation proper is the Location Quotient (LQ) which compares the share of a sector in the regional economy with the share of a sector in the national economy. Condition for selection of priority sectors is value of a location quotient of more than 1.5 i.e. only sectors that are at least 1.5 times the share in a regional economy than they do in the national economy! For

\footnotetext{
${ }^{1}$ NACE is the acronym for "Nomenclature statistique des activités économiques dans la Communauté européenne"; NACE Rev. 2 - Statistical classification of economic activities in the European Community; ISBN 978-92-79-04741-1, ISSN 1977-0375, EC, 2009
} 
example, LQ for employment is given in formula 1 , with e = (sectoral) employment in region and $\mathrm{E}=$ (sectoral) employment in nation, for NACE sector $\mathrm{X}$ :

$$
L Q=\frac{\frac{e_{\text {NACE } X}}{e_{\text {total }}}}{\frac{E_{\text {NACE } X}}{E_{\text {total }}}}
$$

Two more characteristics must be considered for selected priority sectors: Absolute Size: this characteristic will exclude sectors which are employing to small number of people: and Growth: with this characteristics it is possible to differentiate sectors whether they are emerging or mature sectors which should be restructured first. With these two characteristics, additional thresholds were defined, particularly minimum size of absolute value for each indicator. Analysing data for period of 5-6 years only those NACE 3-digit level sectors are kept as relevant if they show as stable specialisations for at least 3 times for single years across the entire economy.

External experts have defined three sets of indicators that should best describe positions of the regions in terms of specialisation (Kroll, Schnabl \& Horvat, 2017):

(1) Indicators of Economic Potential of the region:

- Employment, according to 2011-2016 labour force survey data,

- Exports, according to 2012-2016 national export statistics;

(2) Indicators of Innovative Potential of the region:

- Innovating firms, according to the 2010-2014 national innovation survey,

- Patents, according to indicators developed by the Mihajlo Pupin Institute, based on data provided by the Intellectual Property Office;

(3) Indicators of Scientific Potential of the region:

- Publications, according to indicators developed by the Faculty of Physics and M. Pupin Institute, based on data collected by the Faculty of Physics, using Web of Science/Frascati classifications of fields of sciences.

All data, necessary for calculation of proposed indicators were provided to external experts and Analytical team by the Republic Statistical Office, with requested levels of details and accuracy. Integration of all three analysed potentials (economic, innovative and scientific) is done by external experts in two steps:

Step 1: Identifying Potential Priority Domains based on Overall Thresholds;

Step 2: Matching of Results with Further Information on "Smartness" - several more indicators are used in order to assess the relevance and potential promise of the identified economic priority domains: total employment, wages, value added, labour productivity, growth in employment.

Steps 1 and 2 have resulted with identification of potentially priority areas of specialisation by regions based on quantitative analysis, and should be basis for EDP process between all interested stakeholders. Integration of all indicators used for quantitative analysis presented within these two steps is done using Excel table with calculated values, selecting NACE 3-digit sectors they fulfil conditions - predefined thresholds (Kroll et al., 2017):

- Region RS11 Belgrade:

- Priority sectors: Computer Programming and ICT; R\&D and Technical Consultancy; Creative Economy; Monetary Intermediation,

- Potentially emerging innovative sectors: Beverages, Pharmaceuticals, Electrical Components, Transport Equipment, 
- Science based sectors: various;

- Region RS12 Vojvodina:

- Priority sectors: Automotive; Agricultural Economy (including processing industries); Petrochemical Industry; Plastics Industry;

- Potentially emerging innovative sectors: Agricultural Machinery, Measurement Instruments

- Science based sectors: Computer Science, Telecommunications

- Region RS21 Šumadija and Western Serbia:

- Priority sectors: Agri-/Horti-/Silvicultural Economy (including processing industries); Automotive; Textile Industry; Plastics Industry; Metal Industry;

- Potentially emerging innovative sectors: Special Purpose Machinery

- Science based sectors: mechanical engineering, pharmacy

- Region RS22 Southern and Eastern Serbia:

- Priority sectors: Agri-/Horticultural Economy (including processing industries); Textile Industry; Rubber Industry; Electrical Engineering;

- Potentially emerging innovative sectors: Food Products, Medical and Dental

- Science based sectors: electrical engineering

\section{IMPLEMENTATION OF S3 IN SERBIA: CHALLENGES BETWEEN PROPOSED METHODOLOGY AND REAL SITUATION IN COUNTRY}

Rigidity of the proposed method of selection with threshold of $L Q>1.5$ and even with reduced threshold of $L Q>1.25$ should be welcomed by the wider public as ability to make priorities without compromise. Still, question on use of complete available data, considering all indicators of economic, innovation and scientific potentials, remain unanswered, although steps 1 and 2 presents sort of mixture of quantitative with qualitative analysis with aim to make more adequate decisions - selections. Exhaustive analysis of statistical data finalised with analytical tool is result of quantitative analysis provided by external experts (FhG institute ISI, Karlsruhe, Germany). Excel table listing all NACE 3-digit sectors they fulfil conditions for selection of potentially priority areas of specialisation by regions should be basis for EDP process between all interested stakeholders; still 0-1 type of table could be source of numerous questions, doubts and mistrust, particularly from stakeholders they represent sectors which are not selected among potentially priority areas of specialisation. Therefore, additional quantitative analysis is recommended by the Analytical team - associates of "Mihajlo Pupin" institute (MPI) and accepted by the Interministerial Working Body (IWB): use of single criterion as aggregate value of all proposed indicators provides rationale for extension of basic S3 approach with implementation of multiple criteria aggregation in mapping exercise. Therefore, MPI associates have applied the Ideal Point Method (IPM) Compromise Programming (Zeleny, 1976). The IPM is implemented as follows: a set $A$ of $n$ sectors is compared with respect to $m$ indicators. All sectors are compared with a sector that has ideal values for all $\mathrm{m}$ indicators, a so-called ideal (a reference sector). A point in $\mathrm{m}$ dimensional space represents each sector from the set $\mathrm{A}$. The point representing the ideal sector is referred to as the ideal sector (ideal point, as name of the method suggested). The distance $d$ (the author of IPM has recommended geometrical distance) of each point from the ideal one is calculated using formula 2 . The sector, whose distance from ideal is the shortest, is the best sector. The calculated distance $\mathrm{d}$ is value which could be used for a ranking list of objects: 


$$
d_{i}=\sqrt[1 / L_{p}]{\sum_{j} k_{j} \times\left(\frac{I C_{j}-C_{i j}}{\left(C_{i j}\right)_{\text {max }}}\right)^{L_{p}}} \quad ; j=1, \ldots, m ; i=1, \ldots, n
$$

where: ICj - a j-th single indicator for 'reference sector', Ci,j - a j-th single indicator of an i-th observed sector, $\mathrm{kj}$ - a weighting factor of a j-th single indicator; $\mathrm{j}$ - number of single indicators; $\mathrm{i}$ - number of observed sectors; Lp - used metrics, di - calculated distance for i-th sector from reference sector. With $\mathrm{Lp}=2$, the formula is a calculation of Euclidean distance, and this case is used by analytical team.

The extension of the quantitative analysis with, recommended by the Analytical team, use of MCDM Ideal Point Method Compromise Programming has provided one more geographical area of analysis - entire country! Therefore, results of this amendment to basic S3 procedure are five ranking lists of NACE 3-digit level sectors-groups: one ranking list for Serbia total and four ranking lists for statistical regions (table 2; data for year 2016, excerption - only first ten NACE 3-digit sectors-groups are presented and for Serbia total only).

Table 2. Ranking list of NACE sectors-groups in Serbia total - excerption, first ten NACE 3-digit level sectors-groups, year 2016

\begin{tabular}{|l|l|}
\hline Rank & NACE 3-digit Sectors - Groups - first ten presented - Serbia total \\
\hline 1. & J62.0 - Computer programming \\
\hline 2. & M73.1 - Advertising \\
\hline 3. & M71.1 - Architectural and engineering activities \\
\hline 4. & A1.1 - Growing of non-perennial crops \\
\hline 5. & G46.9 - Non-spec. wholesale trade \\
\hline 6. & M71.2 - Technical testing and analysis \\
\hline 7. & C28.2 - Manufacture of other general-purpose machinery \\
\hline 8. & $\begin{array}{l}\text { C26.5 - Manufacture of instruments and appliances for measuring, testing and navigation; } \\
\text { watches and clocks }\end{array}$ \\
\hline 9. & C10.8 - Manufacture of other food products \\
\hline 10. & M72.1 - R \& D - Natural Science \\
\hline
\end{tabular}

Source: Analytical team, internal working documents, 2017-2018

Quantitative analysis of economic, scientific and innovative potentials of Serbia in total and in all statistical regions using the basic S3 process of selection of NACE 3-digit potentially priority sectors-groups in four regions and with amendment of ranking list of all NACE 3-digit sectorsgroups created with aggregate criteria (MCDM aggregation and ranking) both for Serbia total and for four regions, all together this information should be a basis for meaningful EDP dialogue!

\section{S3 - challenges between theory and reality in Serbia}

Development and implementation of Smart Specialisation Strategy in Serbia is adventure faced with numerous challenges, some of them will be clarified as follows:

1. Responsibility: which ministry should be in charge of development and implementation of the RIS3 in Serbia?

EU member countries were firstly obliged to develop S3 in order to be eligible for use of structural funds: "This Communication complements the one on the Innovation Union by calling on policymakers in Member States at all levels to act without delay to invest more of the resources still available from the European Regional Development Fund (ERDF) in the present programming period on smart growth" (European Commission, 2010). Seven years later, S3 became new industrial policy for EU - the smart specialisation is, in fact, 
development of sectors of economy based on knowledge, i.e. new industrial policy relying on integration of R\&D and innovation with business: "Investing in a smart, innovative and sustainable Industry - A renewed EU Industrial Policy Strategy" (European Commission, 2017). Unlike already established mind-set in EU with orientation of S3 as main policy instrument for development of economy, situation in both Western Balkan countries which are in process of development of RIS3 is rather puzzled. In the Republic of Serbia (RS) and in the Montenegro (MNE), ministries which are responsible for development of RIS3 are ministries in charge for science: Ministry of Education, Science and Technological Development in RS and Ministry of Science in MNE. Having in mind fact that development of RIS3 in both countries is supported by the Joint Research Centre of EU IPTS (Seville, Spain), it is reasonable to expect that implementation of the RIS3 will be realised through activities of (and financed by) ministries in charge of economy and other related ministries, with, eventually, coordinating role of ministries in charge of science for better allocation of research and innovation resources in countries;

2. Organisation - Motivation I: although development of the RIS3 has all elements of project activity (institution involved, activities and responsibilities with mailstones, results, deliverables, etc. pre-defined and agreed; therefore management, financing, monitoring, etc. are clearly defined) in the Republic of Serbia is, primarily, voluntary based activity. There are no contracts, obligations, and consequently, there is no financing of development of RIS3!? There is budget, with clearly defined roles and obligations, for JRC as supporting institution, but JRC has no obligation for creation of RIS3 in RS. Therefore, development of RIS3 in RS relies on good will and voluntary based engagement of members of Operational and Analytical teams, together with involved associates of the "Mihajlo Pupin" Institute, Republic Statistical Office, Intellectual Property Office, Faculty of Physics, and some others;

3. Financing - Motivation II: Having no project organisation, there is no financing of the development of RIS3 in RS! This challenge, although already mentioned within previous challenge, must be stressed as serious issue which could increase risk for successful realisation of RIS3 to the unacceptable level;

4. Mobilisation of stakeholders - Motivation III: Stakeholders, particularly representatives from companies, but also from all other relevant institutions, can be mobilised if they could find interest for this engagement. Adoption of the RIS3 in RS has no direct consequences in terms of launching of new programme with specific (and already allocated) funds, primarily addressed to companies which should develop new products/services in cooperation with R\&D sector. Such situation hardly could motivate stakeholders for active involvement in development of RIS3, particularly during EDP process which should serve as dialogue for (re)definition and adoption of proposed priority areas (NACE 3-digit sectors/groups);

5. Legal framework: Because of un-clear position of involved institutions ("who is responsible for what"), there is no laws and by-laws with precise definition of the role of RIS3, as well as procedures for financing (budgeting), monitoring, reporting, etc. for the process of implementation of RIS3 in RS;

6. Quantitative vs. qualitative analysis - Selection of priority sectors: Fact based decision making is regular procedure for businesses; surprisingly "believing" could be preferable approach for other sorts of decision, as this is explored in previous article, using wrong figure for GERD and number of researchers in main policy document for scientific community, official S\&T strategy adopted in 2010, ignoring available official statistics (Stefanovic-Sestic \& Kutlaca, 2014). This is a reason for precaution rather than enthusiasm having such exhaustive quantitative analysis provided by external experts (FhG, JRC) and complemented by the Analytical team. Prejudices, hidden interest and political preferences could be stronger argument than data and information based on 
quantification of the available statistics. This challenge could be major obstacle for wider dialogue of involved stakeholders and could lead to wrong decisions;

7. Culture of dialogue: Entrepreneurial Discovery Process (EDP) is one of the key phases in creation of the RIS3, and should be sort of dialogue between involved stakeholders in order to reach consensus in selection of priority areas for smart development. It is necessary to consider findings related to ability and readiness for dialogue: the results of Gert Hofstede's research on the impact of certain components of national cultures showed that people in Serbia are characterised by the disrespect of institutions and tendency towards short-term orientation rather than strategic long-term thinking (Hofstede \& Hofstede, 2005). Combining these findings with inherited legacy from socialist period of autocratic decision making it is reasonable to assume that organisation of wider democratic dialogue could be serious challenge.

\section{S3 - FURTHER STEPS}

First year of development of the RIS3 in Serbia has ended with quantitative analysis and mapping of economic, innovative and scientific potential in Serbia (Kroll et al., 2017), complemented with ranking lists of NACE 3-digit level sectors-groups in Serbia total and for all four regions using MCDM Ideal Point Method Compromise Programming, developed by the IMP associates within the Analytical team. Following road map, in the second year (2018) should be realised third phase, i.e. Entrepreneurial discovery process (EDP), or dialogue between all stakeholders and qualitative analysis of proposed priority NACE sectors-groups and ranking lists of NACE sectors in regions and for Serbia in total. Following original S3 methodology and advices from external experts (JRC), EDP should be organized for all selected areas of smart specialisation, therefore, IMP associates within the Analytical team has proposed generalisation of ranking list of NACE 3-digit level sectors-groups in Serbia total. This generalisation has led to the following proposal:

1. Priority areas - vertical:

- Digitalisation of the Economy and Society

- Smart Agriculture - Food and Health

- Smart Industry 4.0 and Smart Materials

- Cultural Heritage and Cultural Industries

2. Priority areas - horizontal: KET; ICT; Environmental protection; Energy Efficiency

3. With Key Emerging Technologies (KET): Micro and Nano-electronics; Nano-technologies; Industrial biotechnology; Advanced materials; Photonics; Advanced technologies in manufacturing.

Preparation of conditions for organisation of EDP is ongoing activity in the time of writing this article, and results of this phase together with creation of final RIS3 document together with plan for implementation of RIS3 in Serbia are the future steps, and possible subject for future writing about RIS3 in Serbia. Main outcome of all mentioned activities should be consensus about identified priorities, as well as wider understanding of necessity of creation of National Innovation System in Serbia (Edquist \& Johnson, 1997).

\section{ACKNOWLEDGEMENT}

Research presented in this paper was supported by the Ministry of Education, Science and Technological Development of the Republic of Serbia, under the project: "Research and Development of the Platform for Science Based Management of the Scientific and Technological Development of the Republic of Serbia", reg. no. III 47005. 


\section{REFERENCES}

Edquist, C., and Johnson, B., (1997). "Institutions and Organizations in Systems of Innovation", in Edqust, C. (ed.), "Systems of Innovation", London, Pinter

European Commission (2010). Regional Policy Contributing to Smart Growth in Europe 2020, COM (2010) 553 final.

European Commission (2017). Communication from the Commission to the European Parliament, the European Council, the Council, the European Economic and Social Committee, the Committee of the Regions and the European Investment Bank 'Investing in a smart, innovative and sustainable Industry - A renewed EU Industrial Policy Strategy'. Brussels, 13.9.2017, COM(2017) 479 final.

Foray, D., David, P.A. \& Hall, B. (2009). Smart Specialisation - The Concept. Knowledge Economists Policy Brief no. 9, Knowledge for Growth Expert Group.

JRC and IWB (2017). Smart Specialisation \& Organisational Development: Roadmap 2017-2018 for the pilot project with Serbia. Internal working document

Kroll, H., Schnabl, E., \& Horvat, D. (2017). Mapping of economic, innovative and scientific potential in Serbia. Karlsruhe: Fraunhofer ISI.

Kutlača, Đ., Semenčenko, D., Nedović, V., (2016). Smart specialization in Serbia - Challenges for governance of research and innovation, 23th scientific conference Technology, culture and development, proceedings, Tivat, Montenegro, Association "Technology and culture", ISBN 97886-915151-3-7, COBISS.SR-ID 230384908, pp. 7-21

Foray, D. (2009). Measuring smart specialization: entrepreneurial discovery, new activities and inclusiveness, Smart Specialisation - The Concept. Knowledge Economists Policy Brief 9, June 2009

Hofstede G. \& Hofstede G.J. (2005). Cultures and Organizations. McGraw-Hill

S3 Platform (2012). Guide to Research and Innovation Strategies for Smart Specialisation (RIS3). Retrieved from:

http://ec.europa.eu/regional_policy/sources/docgener/presenta/smart_specialisation/smart_ri s3_2012.pdf

Semencenko, D., Kutlaca, Dj., (2018). Shaping National Innovation System in Small, Transitional Economy - Case of Serbia. Publisher: University of Belgrade, Institute "Mihajlo Pupin" - Science and technology Policy Research Centre. pages: 186. Belgrade

Stefanovic-Sestic S. \& Kutlaca Dj. (2014). Harmonization of the STI statistics in Serbia with EU standards, Proceedings of the XXI scientific conference "Technology, Culture, Development', Tivat, Montenegro, pp. 212-219.

Zeleny, M. (1976). The Theory of the Displaced Ideal. In Zeleny, M., (ed), Multiple Criteria Decision Making, Berlin-Kyoto, Springer-Verlag, pp.153-206

\begin{tabular}{|l|l|}
\hline Article history: & Received: October 30, 2018 \\
\cline { 2 - 2 } & Accepted: December 14, 2018 \\
\hline
\end{tabular}

